\title{
Does justice require genetic enhancements?
}

\author{
Nils Holtug University of Copenhagen, Copenhagen, Denmark
}

\begin{abstract}
It is argued that justice in some cases provides a pro tanto reason genetically to enhance victims of the genetic lottery. Various arguments - both to the effect that justice provides no such reason and to the effect that while there may be such reasons, they are overridden by certain moral constraints - are considered and rejected. Finally, it is argued that justice provides stronger reasons to perform more traditional medical tasks (treatments), and that therefore genetic enhancements should not play an important role in a public health care system.

(Fournal of Medical Ethics 1999;25:137-143)
\end{abstract}

Keywords: Justice; genetic enhancements; genetic lottery; end of medicine

The chances are that you - the reader of this journal - are a reasonably healthy person. I do not mean to say that you are likely to be perfectly healthy; after all, most of us have some medical conditions that cause inconveniences, lost opportunities or even suffering. However, I think it is fair to say that, as far as our health is concerned, most of us are reasonably well off. But not everyone is so fortunate. Here follows a description of some of the patients at the Children's Convalescent Hospital in San Diego:

"On the beds lie the children - the two-year-olds, the four-year-olds, the ten-year-olds, and the teenagers - some whose limbs convulse erratically, others who are unnaturally still ...

"Some of these children will die very young in the bright world of Children's Hospital. For others there will be a succession of hospital rooms, without toys or murals, and a succession of nurses, who may no longer wonder how to extend their hands to elicit a response, who no longer wind music boxes, a succession of rooms, to which the children will be largely oblivious. A few will return, at least for a while, to their parents."

"In one of the rooms at Children's Hospital, a four-year-old boy who looks much younger than his age sits on the floor playing with a toy. $\mathrm{He}$ is afflicted with neurofibromatosis, and his development was quite normal until a year or so ago, when he suffered a massive seizure, which returned him to a state of early infancy. Slowly, the doctors and nurses at Children's have brought him back, watching him reacquire the capacities of a young toddler. Soon his parents will follow his further developmental steps, waiting for the next seizure, wondering how far he will go this time and how much will be lost."

Some of these children have severe diseases that are due to genetic conditions. They will suffer and, in some cases, die at an early age because they were unfortunate enough to come into existence with a (or several) disease-causing genes. Many of us think that, since they cannot possibly be said to deserve these genes or their vast negative effects, they should be compensated in terms of publicly funded health care services, and perhaps in other ways as well.

In the following, I shall spell out in greater detail this argument for compensating people with genetically determined diseases. I shall then argue that, perhaps somewhat surprisingly, it implies that justice may provide us with a reason not only to treat diseases, but also genetically to enhance certain characteristics in people. The reasons I refer to here are pro tanto ${ }^{2}$ reasons - we have $a$ reason to treat and to enhance. However, pro tanto reasons need not be decisive; they may be outweighed by other, stronger reasons. So the pro tanto reason to enhance may be outweighed by conflicting reasons, pertaining either to justice itself or to some other part of our moral system.

There are various ways of drawing the distinction between treatments and enhancements, but I shall take a treatment to be an intervention that aims at curing or reducing the effects of a disease, where a disease is taken to be a departure from species-typical normal functioning. Enhancements, on the other hand, do not aim to cure or reduce the effects of diseases. I draw the distinction in this way because I believe that it is at least close to what many people who believe in the moral significance of the distinction have in mind. 
Since my claim about justice and the pro tanto reason to enhance is controversial, I shall consider various objections and argue that these are not very compelling. Finally, I shall argue that while justice may give us a pro tanto reason for genetic enhancing, it will also (mostly) provide us with a stronger (or overriding) reason not to. This is because more traditional medical tasks - for example, trying to treat severe diseases such as those from which the children at Children's Hospital suffer - are more important.

\section{The genetic lottery}

When we come into existence, we do so with a particular set of genes that we have not chosen or influenced ourselves. I shall refer to this distribution of genes to people as the "genetic lottery". Our lot in this lottery is crucial as to how well our lives go. Some are fortunate, others are not. Some are born healthy and with much potential, others are born with severe, painful diseases that cause them to die young.

The point of introducing the idea of a genetic lottery is that since we have not chosen our genes, we cannot be said to deserve them. Nor can we be said to deserve the benefits we reap or the harms we suffer because of our genetic make-ups, since neither are due to our choices. For instance, a person who needs an expensive medical treatment because he or she suffers from cystic fibrosis has not chosen to need this treatment or even made choices that cause him or her to need it.

Of course, many diseases are more complicated than cystic fibrosis, in that they are partly due to choices. In some such cases, we may be less inclined to say that people are not responsible for them themselves. For instance, what should we say about a case in which a person chooses to smoke although he knows that, because of his genetic make-up, he has an above average chance of developing lung cancer? However, for present purposes, I want to stick to the simpler cases in which people's own choices cannot be said to play a causal role. ${ }^{3}$

John Rawls has famously argued that we have a pro tanto reason to eliminate inequalities between people that are due to natural contingencies, such as the distribution of genes. ${ }^{4}$ In fact, Rawls believes we also have a reason to eliminate inequalities that are due to social contingencies, but my focus here is on the genetic lottery.

However, as some commentators have pointed out, it does not follow from the claim that inequalities are not deserved that they should be eliminated, or, for that matter, that any particular distribution should be implemented. Nevertheless, I believe that the point that certain benefits and harms are not deserved lends son support to the claim that we ought to redistribu的 to accommodate the interests of the worse of Many of us have moral intuitions to the effect tha when people are badly off through no fault of therr own, we have a reason to compensate them, for example, in terms of adequate health case services.

These intuitions can be accounted for in $\frac{0}{0 a}$ number of different ways. We may believe, as do egalitarians, that when inequalities are not deserved we should eliminate them and, for that re $\overrightarrow{g s}$ son, compensate the worse off. Or we may believes, as do prioritarians, that we should simply give pte ority to the worse off, at least when they are not responsible for so being. Or we may believe, as do utilitarians, that we should aim to maximise the sum of utility and that, in general, compensating the worse off, when they are not responsible fer being so, is an efficient way of achieving this aim. Either way, we have a reason to redistribute. Ard we have a reason to provide health care for people who suffer from genetic defects (and, presumable for many other people as well).

However, the misfortunes that people may sutfer in the genetic lottery do not stop at disease. For instance, in a survey of the research done physical attractiveness and how people are pesceived it is concluded that: "The social psych $\Theta$ logical effects of physical attractiveness are perv룡sive, strong, and generally uniform in nature They are such that the physically attractive, whether male or female, old or young, black or white, or of high or low socioeconomic stat receive preferential treatment in virtually evegy social situation examined thus far." 5

Furthermore, other factors with a genetic basis or genetic component, such as intelligence, talen strength and height, are not evenly distributed. While such features may be less important than health, they are still important for the sort opportunities a person has.

The point I want to make here is that if we are inclined to believe that there is a pro tanto reas to compensate people who are worse off because of their lot in the genetic lottery, there is a p एक tanto reason to compensate people whose genes cause them to be worse off because they are leegs intelligent, less talented, less attractive, etc. The argument presented for compensating people with genetically determined diseases also applies these other features.

One way of compensating people would be using gene therapy to enhance various features, or by using genetic engineering to produce hog mones which would have the same effect. If course, it will be a long time before gene therapiōs 
that can enhance, for example, intelligence are available, if this is indeed ever possible. However, today genetic engineering allows us to produce human-growth hormones, and perhaps it will not be too long before gene therapy can be used to make people taller. And there are other, similar cases.

Therefore, we have an issue of whether justice provides a pro tanto reason genetically to enhance people to compensate for their misfortune in the genetic lottery. Many people will want to resist this claim and therefore I shall consider various objections, both to the effect that justice provides no such reason and to the effect that while justice may give us a reason to compensate in this way, there are overriding moral reasons not so to do.

\section{Justice and distributive units}

It may be thought that it is only if we hold the distributive unit of social concern to be utility (welfare) that we shall be inclined to favour genetic enhancements on the grounds of justice. While it is true, it may be argued, that people can be unhappy about not being, for example, very attractive, they are not worse off in the relevant sense, that is, worse off in a sense that would make compensations appropriate. However, I believe that on any plausible view of what the relevant distributive unit is, a pro tanto case can be made for genetic enhancements. Suppose that the relevant unit is resources, or opportunity for acquiring resources. Some people make less money than others because they are less intelligent or less talented. Of course, we can redistribute money to obtain a fair (for example equal) distribution. But perhaps we can also equalise people's monetary possessions by genetically enhancing people who are less talented or intelligent. So resourcist views do not automatically rule out genetic enhancements as a means of compensation.

However, Norman Daniels has come up with a different argument against medical enhancements. He distinguishes between treatments and enhancements along the lines suggested above. He then suggests that "medicine has the role of making people normal competitors, not equal competitors". ${ }^{6}$ So, at least within medicine, what we should aim at is equality in the sense that everyone is a normal competitor (in the sense of having species-specific normal functioning), but we should not provide enhancements for people who are within the range of what is normal. Daniels calls this "the standard model for thinking about equality of opportunity". He contrasts it with "a more radical version", according to which "wherever possible we must actually try to reduce vari- ance in the distribution of capabilities, equalizing them wherever possible". ${ }^{7}$

There is, however, some tension between Daniels's standard model and another claim he makes, namely that we should "mitigate the effects of normally distributed capabilities through restrictions on other inequalities we allow". ' So Daniels, if I understand him correctly, claims that if, for instance, some people are making less money because they are less intelligent, or talented, etc, and are not responsible for so being, we have a reason to compensate them, but in terms of social rather than natural assets.

Daniels, then, seems to accept my claim to the effect that we have a pro tanto reason to compensate people who have suffered bad luck in the genetic lottery, even if the features in question fall within the range of what is normal; however, he adds that compensation for normal features should be dealt with in terms of social assets, and so not in terms of genetic enhancements. But if genetic interventions are appropriate compensation in some cases (that involve treatments) but not in others (that involve enhancements), we must ask what the relevant difference between the cases is supposed to be.

As a defence of his claim that medical enhancements are not appropriate compensation, Daniels argues that his standard model captures our actual concerns about equality better than the more radical version. However, I do not think that this defence is very compelling. First of all, Daniels compares his standard model to a view that is not very plausible. According to the radical version, inequalities in capabilities should be neutralised. But why should we insist on equalising such differences if there are alternative ways of compensating the worse off that are just as good or even better? Rather, we should aim at the best available compensation, and in some cases this may involve medically improving normal capabilities, while in others it may involve compensating in terms of social assets.

Secondly, I am not so sure that Daniels is quite right about what our actual concerns are. Suppose that a boy is constantly teased because his ears stick out. And suppose that, from this boy's point of view, the best available compensation would be a surgical enhancement. I am inclined to think that many of us would favour surgery in such a case.

Daniels does claim that "we generally resist assimilating these cases of enhancement to cases of treatment because we do not see them as meeting important needs". ${ }^{8}$ However, while we may not want to describe surgery for sticking-out ears as meeting an important need, we would have to be 
very insensitive indeed to claim that there is no reason to fulfil the boy's desire for surgery. Nevertheless, Daniels may be correct in assuming that we believe that it would be much more important to provide treatment for another boy with, for example Lesch Nyhan syndrome.

But granting this to Daniels hardly establishes his claim that, according to our actual concerns, medical enhancements do not fall within the limits of justice. An alternative account may be introduced, according to which we believe that as far as justice is concerned, there is sometimes a reason to compensate people for their misfortune in the genetic lottery in terms of medical enhancements but that, in general, there is a much stronger though similar reason medically to compensate people who have fared significantly worse in this lottery, in that they have ended up with severe (or even less severe) diseases. I shall develop this idea further in the final section of this article.

Finally, I do not think that Daniels really tells us what the relevant difference between medical treatments and medical enhancements is supposed to be. He claims that we believe intuitively that there is a difference, but this is an intuition that may have to be rejected if it turns out that, like many other firmly held moral views, it is baseless. This becomes particularly acute in his own example of two boys, both of whom, it is predicted, will attain an adult height of $160 \mathrm{~cm}$. One, however, has a growth-hormone deficiency resulting from a brain tumour, while the other has short parents and is short because of his (normal) genotype. As Daniels remarks, while the causes of their shortness may be different, they both suffer the same undeserved disadvantages in a "heightist" society, and they are both victims of the natural biological lottery. So how can it be right to treat these two cases differently?

Another suggestion as to why justice does not require genetic enhancements comes from Allen Buchanan. Buchanan defends a principle of justice according to which "other things being equal, no person should be barred from the chance to have a minimally decent life as a result of undeserved natural (or social) deficits". 9 So disadvantages resulting from the genetic lottery do not require compensation unless they preclude people from reaching a certain decent minimum. Assuming, then, that the genetic disadvantages that might "require" enhancements are generally not severe enough to preclude people from reaching this minimum, we generally do not have a reason to perform enhancements. (Actually, this is not quite right. There are people who fall below the minimum for [wholly or partly] independent reasons, but who can nevertheless be raised b performing genetic enhancements).

Buchanan may either be claiming that, once the decent minimum is reached, justice does not prof vide a pro tanto reason to improve a person's coro dition, or claiming that, all told, justice provides no reason to so improve. Since I am present concerned with pro tanto reasons, I shall addre the former claim, although this might not be whog Buchanan has in mind. So the question is, does justice provide a pro tanto reason to raise people above the minimal level?

I, myself, find it very difficult to understand whe one should be troubled by a disadvantage th precludes a person from reaching the minimunis but not at all by a disadvantage that is compatible with reaching it. Changes in a person's level of benefits may be very gradual, and to suggest a particular level where her disadvantage no longer matters seems arbitrary. Why should our concer $\vec{n}$ for disadvantaged individuals suddenly pop out of existence once the minimum is met?

Of course, there is an issue of what counts as $\overrightarrow{\&}$ decent minimum. The higher the minimum, the more plausible it may seem that there is no (nof even a pro tanto) reason to compensate peop who have reached it. But note that the higher the minimum, the larger the amount of cases in whic\% people are prevented from reaching it due to fea tures that have nothing to do with diseases.

Buchanan does acknowledge that we ma believe that it would be a good thing to provide benefits to people who already have a minimali decent life, but goes on to claim that the reason do so need have nothing to do with justice ${ }_{0}^{(\mathbb{D})}$ However, it seems to me that the reason to provide such benefits is (sometimes) of the very same kind as the reason to provide benefits to people wit for example, cystic fibrosis - people have been dis advantaged in the genetic lottery through no faut of their own.

Rather, as I shall suggest in the final sectio there is always a reason to compensate people who have been disadvantaged in the genetic lottery, but this reason can be outweighed by more urgeat reasons to compensate people who have sufferet greater disadvantages. So while there is sometimes a pro tanto reason to perform genetic enhance ments, these will (mostly) be outweighed by stronger reasons to perform other medical tas instead.

\section{The end of medicine}

Perhaps there are other reasons, outside the realm of justice, why we should resist medical enhance ments. It has been suggested that such enhance ments do not comply with the end of medicise 
and, for that reason, are suspect. Here, one advocate of this view, David Hyman, addresses the issue of cosmetic surgery:

"Cosmetic surgery ... collapses the distinction between health and the wishes or happiness of the patient. ... Necessity, requiring intervention, is constituted in the disease rather than in the patient's expressed desires. ... The physician's privilege to refuse to intervene is predicated on a consistent goal of health. ... Medicine is debased as it becomes the handmaiden of vanity and selfindulgence, in the name of 'being your best'."

The core idea seems to be that medicine has an identifiable goal or end, and that this end establishes the limits as to what goals medicine ought to be used to achieve. This end is defined in terms of "a consistent goal of health". So whereas medicine should be used to treat diseases, it should not be used to enhance normal features in people.

There is an issue here of whether the end of medicine can really be restricted to a consistent goal of health. Many of the tasks that are currently dealt with within medicine do not accurately fit this description. Consider, for instance, abortions or surgery for projecting ears.

In any case, there is a more serious objection to Hyman's view. Let us, for the sake of argument, grant him that medicine has a well-defined goal or end. Why then should medicine not be used also to promote other ends? Consider this analogy. School-teachers are trained to educate children. But it is hardly plausible to argue that, for this reason, they ought not to use their skills to write poetry.

More technically, the "consistent goal of health" to which Hyman refers can be interpreted as a descriptive notion that somehow captures the way that medicine is actually practised. In which case, we are left wondering why this notion should say anything about how medicine ought to be used. Or it can be interpreted as a (partly) evaluative notion, that says something about the proper aims of medicine; but then we need an explanation of why the evaluative features captured in this notion that rule out medical enhancements are valid or important. And while I cannot rule out that such an explanation can be given, I have yet to see a plausible suggestion as to how it might work.

\section{The doctrine of correcting and enhancing in medicine}

It may be argued that I have not done justice to our actual moral intuitions about genetic enhancements. When discussing Daniels's standard model, I considered the view that justice or fairness does not require enhancements; I now want to consider the issue of whether there are other moral values that might be brought into play, that would speak against such a medical practice.

\section{Consider:}

The Doctrine of Treating and Enhancing in

\section{Medicine}

Medical treatments are inherently more important than medical enhancements.

This doctrine is intended to capture some important moral intuitions, for example to the effect that there is a moral difference between using genetic engineering to treat cystic fibrosis and using it to enhance a person's (normal) height. Note that the doctrine claims that treating is inherently more important, and not that it is more important because it has better consequences.

I have deliberately made the doctrine rather vague, in that it does not specify to what extent medical treatments are more important or urgent than enhancements. It is both compatible with an absolute constraint against medical enhancements and with the claim that enhancements are only slightly less important than treatments, although, in order for it to have any real force, presumably it must claim that enhancements are significantly less important. Furthermore, I suppose that some adherents of this doctrine will want to claim that while medical treatments have a positive moral value, medical enhancements have a negative moral value.

However, I believe that this doctrine does not adequately capture our intuitions. The standard way of testing such doctrines is to come up with two cases that differ only regarding the factor that the doctrine claims to be morally important, in our case, treatments versus enhancements. So consider the following two cases. ${ }^{12}$ Jane is infected with HIV and she is about to develop AIDS. However, there is a new kind of gene therapy available that will boost her immune system bring it back to normal - and so ensure that she never develops this disease. By giving her the therapy, we would be providing a treatment, since we would be bringing her immune system back to normal.

In our second case, Helen has not yet been infected with HIV but, since she is a haemophiliac and since blood reserves at the hospital have not been screened for HIV, it is only a matter of time before she is infected, unless, that is, a new sort of gene therapy is performed on her that will make her immune. By giving her the therapy we would be enhancing her immune system, since we would 
be giving her a desirable property that people do not normally (or naturally) have.

Intuitively, it does not seem less important to provide the gene therapy for Helen than to provide (the other kind of) gene therapy for Jane. But this is what the doctrine of treating and enhancing in medicine says is the case. Therefore, this doctrine does not really capture our intuitions about treating and enhancing.

I need to make two remarks about my argument against the doctrine of treating and enhancing. Firstly, since I first introduced the cases of Jane and Helen, evidence has been put forward in support of the claim that perhaps some people have genotypes that make it less likely that they will be infected with HIV. Perhaps they are even immune. This evidence may threaten my claim that people do not normally or naturally have the desirable features that Helen may acquire. However, suppose no one had such features. Would that really make a difference as to how we should morally evaluate Helen's therapy? I very much doubt it.

Secondly, note that I am not in my argument using what Shelly Kagan has called a contrast argument. ${ }^{13}$ In a contrast argument, it is argued that if two cases only differ regarding one factor, and there is a moral difference between them, then the moral difference can be attributed to the differing factor, and this factor will then make a moral difference in any two cases that differ regarding it. Alternatively, if the two cases do not differ morally, then the factor never makes a moral difference. However, as Kagan points out, a factor may make a moral difference sometimes but not always (depending on which other factors are present). I am not using this kind of argument since I am not arguing that it can never make a moral difference whether a therapy is a treatment or an enhancement. I am arguing that since it does not always make a moral difference, the doctrine of treating and enhancing cannot be right. Admittedly, since I do not argue that it never inherently matters whether a treatment or an enhancement is performed, my argument is limited, but that is inevitable.

Perhaps a different definition of "treatment" would confer greater plausibility on the doctrine of treating and enhancing. Above, I took a treatment to be an intervention that aims at curing or reducing the effects of a disease, where a disease is taken to be a departure from speciestypical normal functioning. However, this definition may be broadened to include the prevention of diseases as well. Since Helen's therapy will prevent her from being infected with HIV, it should not be considered an enhancement but merely a零 instance of disease-preventing treatment.

But then recall Daniels's case of the two boys who are both predicted to be very short, on because of a growth-hormone deficiency, the other because of his (normal) genotype. If we werê to provide growth hormones for the second child we would not be providing a treatment, eve䨌 according to our new definition. But why should that matter? Both boys have a disadvantage (in 2 heightist society) they have not deserved because of their misfortune in the natural lottery. While may matter that neither is responsible for tho cause of his disadvantage, it does not seem to matter what the exact cause is - rather, it is thie effect, and the fact that they are not responsible for it that matters.

\section{Justice in health care}

To sum up, I have argued that a plausible and influential line of reasoning that supports cons pensating people who have severe diseases be cause of their misfortune in the genetic lottery als speaks in favour of genetic enhancements. Justice requires genetic enhancements in the sense that provides a pro tanto reason to make such enhancements available to (some) victims of the genetic lottery. Furthermore, I have argued th such enhancements cannot be ruled out on the basis of the claim that they do not conform to the end of medicine or by appealing to the doctrine of treating and enhancing in medicine, since neithe of these invoke values that are very plausible.

However, while justice provides us with a pro tanto reason to perform genetic enhancements, 迷 also provides us with reasons to perform othe tasks, such as providing medical care for peopis with serious diseases such as the four-year-old boy in Children's Hospital, and even for people with less serious diseases. Since the amount of resources available in the health care system or, general, for compensating victims of the genetio lottery, is limited (even if we throw in extra resources, this is still the case), we shall have to prioritise. And, although I cannot argue this poiro here, I believe that when prioritising, we shourer give priority to the worse off. ${ }^{14}$ It simply mattes more to provide benefits for the worse off than fof the better off. Therefore, in general, it matters more to provide health care services for peopf with serious diseases than to provide genet. enhancements.

But, of course, there may be exceptions. Mayb? a child who is very unhappy about being short, a in Daniels's example, is a case in point. Maybe \& is as urgent to provide a growth hormone for this child as it is to provide medical treatment for 
person who has, say, a broken wrist. Obviously, though, we cannot answer this question adequately if we do not know the proper unit of social concern, and space does not allow me to discuss this issue here. So let me merely point out that I have already provided a reason to believe that, on any plausible view on what the proper unit is, there will be a pro tanto case for medical enhancements.

A further issue that would have to be considered, though, is what the long term effects would be of giving to certain children, for example, growth hormones, or appropriate kinds of gene therapy. It may be argued that giving in to heightist ideals in this way will just further intolerant attitudes in society and so, even if we restrict ourselves to the issue of justice, such medical enhancements will be counter-productive in the long run. This is a legitimate worry, but one based on predictions very difficult to assess. How, exactly, will medical enhancements affect social attitudes?

Another worry about long term effects that has received a great deal of attention is the risk of a slippery slope. I discuss this in some detail elsewhere. ${ }^{15}$

These are difficult issues, and I cannot discuss them further here. However, I believe I have provided a case for the claim that justice sometimes gives us a pro tanto reason for making genetic enhancements available; however, I have also suggested that, since justice generally gives us stronger reasons to perform other tasks such as providing treatments for people with severe diseases, perhaps, at the end of the day, genetic enhancements should not play an important role within publicly funded health care. What role, if any, they should play in private health clinics is a complicated matter that, again, I cannot address here.

\section{Acknowledgements}

I would like to thank Roger Crisp, Klemens Kappel, Kasper Lippert-Rasmussen and Julian Savu- lescu for helpful comments on an earlier version of this article.

Nils Holtug, PhD, is Assistant Professor in the Department of Philosophy, University of Copenhagen, Denmark.

\section{References and notes}

1 Kitcher P. The lives to come. The genetic revolution and human possibilities. London: The Penguin Press, 1996:13-14.

2 The term pro tanto reason was introduced into modern moral philosophy by Shelly Kagan, who writes: "A pro tanto reason has genuine weight, but nonetheless may be outweighed by other considerations. Thus, calling a reason a pro tanto reason is to be distinguished from calling it a prima facie reason, which I take to involve an epistemological qualification: a prima facie reason appears to be a reason, but may actually not be a reason at all, or may not have weight in all cases it appears to. In contrast a pro tanto reason is a genuine reason - with actual weight - but it may not be a decisive one in actual cases." The limits of morality. Oxford: Clarendon Press, 1989: 17. The important point which is relevant for the paper is that a pro tanto reason is a genuine reason, but may be outweighed by other stronger reasons (like my reason to go shopping may be outweighed by my stronger reason to finish my paper).

3 I consider the issues of responsibility and justice in more complicated cases that involve choices, in Holtug N. Genetic knowledge in a just society. In: Thompson $A$, Chadwick $R$, eds. Genetic information: acquisition, access, and control. New York: Plenum Publishing Corporation (in press).

4 Rawls J. A theory of justice. Oxford: Oxford University Press, 1971: 65-80.

5 Bersheid E, Gangestad S. The social psychological implications of facial physical attractiveness. Clinics in Plastic Surgery 1982; 9:290.

6 Daniels $\mathrm{N}$. The genome project, individual differences, and just health care. In Murphy TF, Lappé MA, eds. Fustice and the human genome project. Berkeley: University of California Press, 1994:122.

7 See reference 6:125.

8 See reference 6:126.

9 Buchanan A. Equal opportunity and genetic intervention. Social philosophy and Policy 1995;12:129.

10 See reference 9:130.

11 Hyman DA. Aesthetics and ethics:the implications of cosmetic surgery. Perspectives in Biology and Medicine 1990;33: $193,197,201$.

12 See also Holtug $N$. Creating and patenting new life forms. In: Singer P, Kuhse $\mathrm{H}$, eds. $A$ companion to bioethics. Oxford: Basil Blackwell, 1998.

13 Kagan S. The additive fallacy. In: Fischer JM, Ravizza M, eds. Ethics. Problems and principles. Fort Worth: Harcourt Brace Jovanovich College Publishers, 1992.

14 See Parfit D. Equality or priority? The Lindley lecture 1991, University of Kansas, 1995, and reference 3.

15 Holtug $\mathrm{N}$. Human gene therapy: down the slippery slope? Bioethics 1993;7: 402-19. 